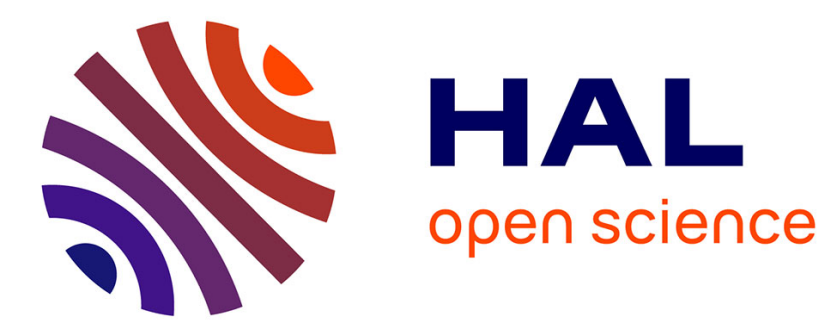

\title{
Optimal operation of sublimation time of the freeze drying process by predictive control: Application of the MPC@CB Software
}

\author{
Nawal Daraoui, Pascal Dufour, Hassan Hammouri, Aurélie Hottot
}

\section{To cite this version:}

Nawal Daraoui, Pascal Dufour, Hassan Hammouri, Aurélie Hottot. Optimal operation of sublimation time of the freeze drying process by predictive control: Application of the MPC@CB Software. EFCEEuropean Symposium on Computer Aided Process Engineering (ESCAPE), Jun 2008, Lyon, France. pp.453-458. hal-00352454v2

\section{HAL Id: hal-00352454 \\ https://hal.science/hal-00352454v2}

Submitted on 22 Jan 2009

HAL is a multi-disciplinary open access archive for the deposit and dissemination of scientific research documents, whether they are published or not. The documents may come from teaching and research institutions in France or abroad, or from public or private research centers.
L'archive ouverte pluridisciplinaire HAL, est destinée au dépôt et à la diffusion de documents scientifiques de niveau recherche, publiés ou non, émanant des établissements d'enseignement et de recherche français ou étrangers, des laboratoires publics ou privés. 
This document must be cited according to its final version which is published in a conference proceeding as:

N. Daraoui ${ }^{1}$, P. Dufour ${ }^{1}$, H. Hammouri ${ }^{1}$, A. Hottot ${ }^{1}$,

« Optimal operation of sublimation time of the freeze drying process by predictive control: Application of the MPC@CB Software », Proceedings of the 18th European Symposium on Computer Aided Process Engineering (ESCAPE) 2008, vol. 25, pp. 453-458, Lyon, France, June 1-4 2008. http://dx.doi.org/10.1016/S1570-7946(08)80080-6

All open archive documents of Pascal Dufour are available at: http://hal.archives-ouvertes.fr/DUFOUR-PASCAL-C-3926-2008

The professional web page ( $\mathrm{Fr} / \mathrm{En}$ ) of Pascal Dufour is: http://www.lagep.univ-lyon1.fr/signatures/dufour.pascal

1

Université de Lyon, Lyon, F-69003, France; Université Lyon 1;

CNRS UMR 5007 LAGEP (Laboratoire d'Automatique et de GEnie des Procédés),

43 bd du 11 novembre, 69100 Villeurbanne, France

Tel +33 (0) 472431845 - Fax +33 (0) 472431699

http://www-lagep.univ-lyon1.fr/ http://www.univ-lyon1.fr http://www.cnrs.fr 


\title{
Optimal operation of sublimation time of the freeze drying process by predictive control: Application of the MPC@CB Software
}

\author{
N. Daraoui, P. Dufour, H. Hammouri, A. Hottot \\ Université de Lyon, F-69000,, Lyon, France; Université Lyon 1, F-69622, Lyon, France \\ CNRS, UMR 5007, LAGEP (Laboratory of Process Control and Chemical \\ Engineering), 43 bd du 11 novembre,F- 69622 Villeurbanne, France \\ dufour@lagep.univ-lyonl.fr
}

\begin{abstract}
This paper presents the application of a model based predictive control strategy for the primary stage of the freeze drying process, which has not been tackled until now. A model predictive control framework is provided to minimize the sublimation time. The problem is directly addressed for the non linear distributed parameters system that describes the dynamic of the process. The mathematical model takes in account the main phenomena, including the heat and mass transfer in both the dried and frozen layers, and the moving sublimation front. The obtained results show the efficiency of the control software developed (MPC@CB) under Matlab. The MPC@CB based on a modified levenberg-marquardt algorithm allows to control a continuous process in the open or closed loop and to find the optimal constrained control.
\end{abstract}

Keywords: Freeze drying, moving boundary, non linear distributed parameter systems, model based predictive control, internal model control.

\section{Introduction}

Freeze drying is a separation process in biotechnology, food and pharmaceutical industries, frequently used to stabilize and preserve the products [1-2]. Compared with conventional drying techniques, freeze drying is generally considered to produce highest quality dried products. In freeze drying, major costs being apportioned are: the energy for sublimation of frozen solvent during the primary drying stage, the energy for the removal (desorption) of bound (unfrozen) solvent during the primary and secondary drying stages, the energy to support vacuum and labor, and overhead costs which are all a function of the drying time. Moreover, one very important parameter in the study of freeze drying is the temperature of the product which must carefully be controlled during the primary and the secondary stages of freeze drying.

A number of freeze-drying models have been published in the literature to describe the freeze-drying process. The model of Liapis and Litchfield [3] was seen to be more accurate than the model of King [4]. The sublimation model was then improved upon [5] by including the removal of bound water in equations. This model is commonly known as the "sorption-sublimation model". Various numerical methods can be used to solve the governing equations. Liapis and co-workers used a one-dimensional method which the method of orthogonal collocation [6] was applied to solve the equations. Ferguson et al. [7] used the finite element method to solve the governing equations. 
Very few papers deal with the on-line optimal control of freeze drying. The optimal control of the primary and secondary drying stages of bulk solution freeze drying in trays was formulated and solved by [8]. The contribution of this paper is therefore to provide a model predictive control (MPC) framework, as applied in [9], to minimize under constraints the drying time during the primary stage of the freeze drying process of Bovin Serum Albumin (BSA) solution, a formulation whose physical data are available and freeze drying were already carried out. To satisfy this purpose, a control software (MPC@CB) is used, allowing solving any other constrained optimal control problems for any processes. The dynamics of the moving sublimation ice front and the temperature profiles of the product are presented here.

\section{Freeze drying process}

Freeze-Drying is a drying process where the solution is first frozen, thereby converting most of the water to ice, and the ice is removed by sublimation at low temperature and low pressure during the primary drying stage of the process. Since freeze drying is the most complex and expensive technique of drying, its use is usually restricted to delicate heat sensitive products. In the pharmaceutical industry, the solution is normally filled into glass vials, the vials are placed on temperature controlled shelves in a large vacuum chamber, and the shelf temperature is lowered to freeze the product. After complete solidification, the pressure in the chamber is lowered to initiate rapid sublimation.

To carry out the objective of this paper, we consider a one-dimensional freeze drying model based on the work of Liapis and Sadikoglu [8]. During the primary drying, the vial contains two regions: a dry layer, in which the majority of water was sublimated and a frozen layer. These two areas are separated by a moving interface called the sublimation front. In this work, it is assumed that [5]:

- One dimensional heat and mass transfer.

- The sublimation front is planar and parallel to the horizontal section of the vial.

- The gas phase inside the pores of the dry layer is composed only of pure water vapor, i.e. the effect of inert gas is negligible because the amount of inert gas in the drying chamber is much smaller than that of water vapor.

- The value of the partial pressure of water vapor at the top of the dry layer is equal to the total pressure in the sublimation chamber.

- The frozen region is considered to be homogeneous with uniform thermal conductivity, density and specific heat.

The mathematical model consists of the unsteady state energy balance in the dried and frozen regions:

$$
\left\{\begin{array}{l}
\frac{\partial T_{1}}{\partial t}=\frac{k_{1 e}}{\rho_{1 e} c_{p 1}} \frac{\partial^{2} T_{1}}{\partial z^{2}}-\frac{c_{p g}}{\rho_{1 e} c_{p 1}} \frac{\partial\left(N_{w} T_{1}\right)}{\partial z}-\frac{\Delta H_{v} \rho_{1}}{\rho_{1 e} c_{p 1}} k_{d} C_{s w} \quad, t>0,0<z<H(t) \\
\frac{\partial T_{2}}{\partial t}=\alpha_{2} \frac{\partial^{2} T_{2}}{\partial z^{2}}, t>0, H(t)<z<L \\
\frac{d H}{d t}=-\frac{1}{\rho_{2}-\rho_{1}} N_{w}, \quad t>0, z=H(t) \\
\frac{\partial C_{s w}}{\partial t}=-k_{d} C_{s w} \quad t>0, \quad 0<z<H(t)
\end{array}\right.
$$


Where $T_{1}$ is the dried layer temperature, $T_{2}$ is the frozen layer temperature, $N_{w}$ is the mass transfer flux of the water vapour, $\mathrm{C}_{\mathrm{sw}}$ is the bound water and $\mathrm{H}$ is the sublimation interface. The different parameters of the model are presented in [12]. In this work, we use a simplified equation to describe the dynamic of the mass flux based on the diffusion equations of Evans. The equation is given by the following expression:

$$
N_{w}=\frac{-M_{w} k_{1}}{R_{i g} T_{1} H}\left(p_{H}-p_{0}\right), t>0
$$

Where $\mathrm{p}_{0}$ and $\mathrm{p}_{\mathrm{H}}$ is the partial pressures of water vapor at $z=0$ and $z=H(t)$ respectively. The pressure boundary condition at the top surface of the material being dried is defined as a constant pressure inside the drying chamber, and the vapor pressure at the sublimation interface is defined as an equilibrium vapor pressure according to the temperature of the interface.

The initial conditions for the equation (1) are given by:

$$
\begin{cases}T_{1}(z, t)=T_{2}(z, t)=T^{o} & \text { for } 0 \leq z \leq L, t=0 \\ H(t)=0^{+} & \text {for } t=0 \\ C_{s w}(z, t)=C_{s w}^{0} & \text { for } 0 \leq z \leq L, t=0\end{cases}
$$

The boundary conditions for the equations (1) are as follows:

$$
\left\{\begin{array}{l}
-k_{1 e} \frac{\partial T_{1}}{\partial z}=q_{1} \quad, \quad t>0, z=0 \\
-k_{1 e} \frac{\partial T_{1}}{\partial z}=-k_{2} \frac{\partial T_{2}}{\partial z}+\left(-\Delta H_{s}+\frac{\rho_{2} c_{p 2} T_{2}-\rho_{1} c_{p 1} T_{1}}{\rho_{2}-\rho_{1}}\right) N_{w}, \quad t>0, z=H(t) \\
-k_{2} \frac{\partial T_{2}}{\partial z}=q_{2} \quad, \quad t>0, z=L
\end{array}\right.
$$

Where $\mathrm{T}_{1 \mathrm{p}}(\mathrm{t}), \mathrm{T}_{\text {up }}(\mathrm{t})$ are respectively the temperatures of the lower and upper heating plates. For general freeze dryers, the temperature of the upper and lower heating plates are the same, i.e. $\mathrm{T}_{\mathrm{lp}}(\mathrm{t})=\mathrm{T}_{\mathrm{up}}(\mathrm{t})$.

The important objective of the on-line control is to decrease the drying time under constraints, while maintaining the quality of the product. Furthermore, an important constraint for primary drying is that one must never allow the product temperature to exceed its glass transition temperature. This constraint can be expressed by:

$$
T_{2}(z, t) \leq T_{g} \quad, \quad H(t)<z<L, \forall t>0
$$

The output variable of the process considered in our control problem corresponds to the measured temperature at the bottom of the vial. In the sequel, it is assumed that only the process output is constrained to satisfy the inequality (5). The second constraints during the primary drying stage of the freeze drying process dealing with the heat flux at the top and bottom surfaces and respectively. Their magnitudes depend respectively on the value of the temperature of the heating plate at the upper surface of the vials, and the temperature of the heating plate at the bottom surface of the vials. These temperatures are assumed to be the same and the manipulated variable $u(t)$ is subjected to the constraints in the following form: 
$T_{\min } \leq u(t)=T_{l p}(t)=T_{u p}(t) \leq T_{\max }, \forall t>0$

\section{Simulation results}

In this study, we are interested to find the optimal on-line tuning of the manipulated variable for the constrained optimization of the sublimation time. To realize the MPC under constraints of the freeze drying process, we used the MPC@CB software ${ }^{1}$ developed with Matlab.

\section{Control Software: main features of MPC@CB}

The codes of the MPC@CB software have been written to run with Matlab. It allows realizing the MPC under constraints of the specified continuous process. The originality of these codes is first the easy use for any continuous SISO process (Single Input Single Output), through the user files (where model equations have to be specified), synchronized by few main standards files (where the user has to make few (or no) changes. The original feature of the software is the straightforward resolution of various model based control problems through different choices:

1. Open or closed loop control.

2. MPC for a trajectory tracking problem, with or without the output constraint.

3. MPC to solve an operating time minimization problem, with or without the output constraint.

The other originality is the method used to develop the codes : it is very easy to introduce new parts in the code, such as :

1. MPC with an user defined control problem.

2. Handle SIMO, MISO or MIMO model .

3. Introduce a software sensor (observer).

4. Apply the software for a real time application [11].

For more the details about the MPC@CB software and the operations conditions, the reader can refer to [12]. The optimal minimization of the drying time under constraints may be equivalent to define the performance index as the maximization of the velocity of the sublimation interface. Since MPC@CB solves a minimization problem, the objective function is:

$$
\min _{u} J(u)=\sum_{j} \frac{1}{\|\vartheta+V(j)\|^{2}} \quad \forall j \in J_{1}^{N_{p}}
$$

accounting for the magnitude constraints for the manipulated variable and the output process. The velocity $\mathrm{V}$ is given by $\mathrm{V}=\mathrm{dH} / \mathrm{dt}$ and $\vartheta>0$ is a small positive parameter, introduced to avoid the division by zero in (7).

In Figure 1, the dynamics of the moving sublimation ice front $H(t)$ and its velocity are presented. The optimization procedure based on the MPC@CB software is iterated until the position $H(t)$ reaches the length $\mathrm{L}$, which means the end of the primary drying stage.

1 ( ) University Claude Bernard Lyon 1 - EZUS. In order to use MPC@CB, please contact the author : dufour@lagep.univ-lyon1.fr 
Optimal operation of sublimation time of the freeze drying by predictive control: Application of the MPB@CB software

The profile of the bottom surface temperature of the materiel being dried, the heating plate temperature, as well as the glass transition temperature are presented in Figure 2. In order to satisfy the output constraint, the temperature is then kept near this constraint value for the rest of the time of the primary drying stage by reducing iteratively the heat flux input. The efficiency of the IMC-MPC strategy over open loop control can be seen: The drying time obtained for the primary drying stage using the MPC@CB software is equal 18 hours, while the required time for the sublimation step is about 24.11 hours in open loop.

\section{Conclusion}

This study tackled the model based predictive control of the primary stage of the freeze drying process. Using the mathematical model of Liapis et al., in which the dynamic of the mass flux was simplified, the model based predictive control of the freeze drying is studied. Taking into account of the non linear partial differential equation model of the process, the idea was to combine the IMC structure and the MPC framework. The resulting IMC-MPC chart corrected the modelling errors introduced in the model based on line optimizer. Constraints on the manipulated variable and controlled variables are handled. This framework was used to optimize the drying time during the primary drying stage of the freeze drying process. The simulations results of the minimization problem were established using the MPC@CB code developed in Matlab. The difficulty related to this problem was the choice of the trajectory given by $\mathrm{u}_{0}$. Since the measured temperature is at the bottom surface of the vial, one may design an observer that estimates the temperatures at different $\mathrm{z}$.

\section{References}

[1] A.I. Liapis, M.J. Pikal, R. Bruttini 1996 Research and development needs and opportunities in freeze drying. Drying Technology, 14, 1265-1300.

[2] A.I. Liapis, R. Bruttini 1994 A theory for the primary and secondary drying stages of the freeze drying of pharmaceutical crystalline and amorphous solutes; comparison between experimental data and theory, Separation Technology, 4, 144155 .

[3] A.I. Liapis, R.J. Litcheld 1979 Optimal control of a freeze dryer-I: theoretical development and quasi-steady state analysis Chemical Engineering Science, 34, 975-981.

[4] CJ. King CJ 1971 Freeze drying Foods CRC Press, Cleveland, OH, 1-54.

[5] R.J. Litcheld, A.I. Liapis 1979 An adsorption-sublimation model for a freeze dryer. Chemical Engineering Science, 34:1085.

[6] A.I. Liapis, L.J. Litcheld 1979 Numerical solution of moving boundary transport problems in finite media by orthogonal collocation. Computers and Chemical Engineering, 3: 615-621.

[7] Ferguson, RW. Lewis, L. Tomosy 1993 A finite element analysis of freeze-drying of a coffee sample Computers Methods Applications Mechanical Engineering 1993, 108: 341-352.

[8] H. Sadikoglu, A.I. Liapis 1997 Mathematical Modelling of the Primary and Secondary Drying Stages of Bulk Solution Freeze-Drying in Trays: Parameter stimation and Model Discrimination by Comparison of Theoretical Results with Experimental Data, Drying Technology, 15: 791-810 
[9] P. Dufour P, F. Couenne, Y. Touré 2003 Model predictive control of a catalytic reverse flow reactor. Control of industrial spatially distributed parameter processes, Special issue of IEEE Transactions on Control System Technology, 11(5) : 705-714.

[10] N. Daraoui, P. Dufour, H. Hammouri 2007 Model predictive control of the primary drying stage of a freeze drying of solutions in vials : a application of the MPC@CB software (part 1). The 5th Asia-Pacific Drying Conference, Hong Kong, China, 2 : 883-888.

[11] K. Abid, P. Dufour, I. Bombard, P. Laurent 2007 Model predictive control of a powder coating process : an application of the MPC@CB software. IEEE Chinese Control Conference, Zhangjiajie, China, 2 : 630-634.

[12] N. Daraoui, P. Dufour, H. Hammouri, A. Hottot 2007 On line constrained optimization of the primary drying stage of lyophilization, American Institute of Chemical Engineers (AIChE) Journal, submitted, ref. AIChE-07-10884.
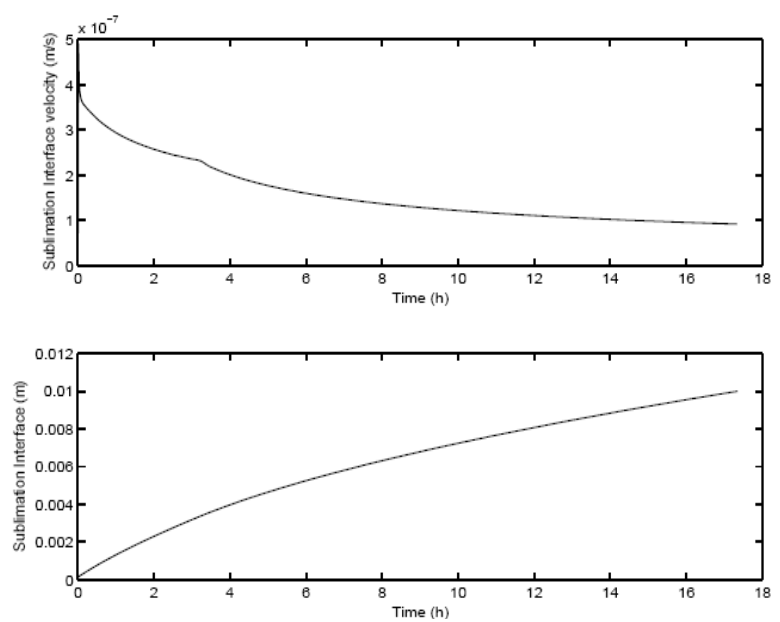

FIG. 1: Optimization of drying time : time variation of the moving interface $\mathrm{H}(\mathrm{t})$ (bottom) and its velocity (top) during the primary drying stage

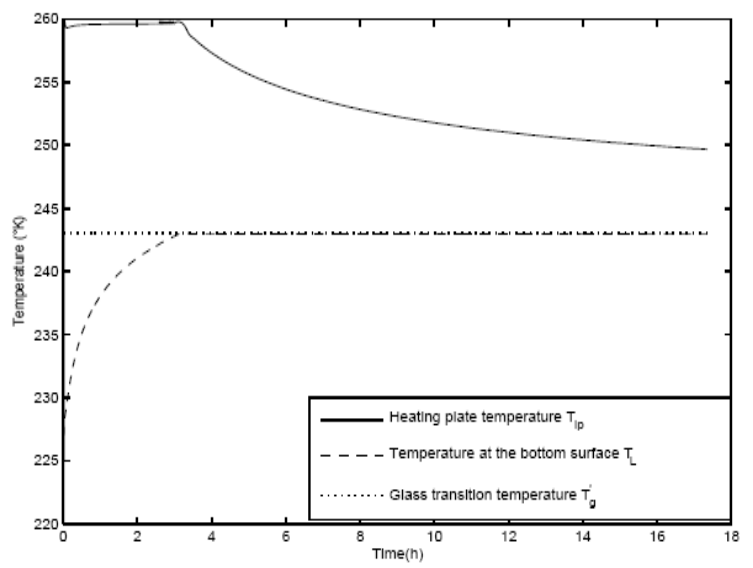

FIG. 2: Optimization of drying time : time variation of the bottom surface and heating plate temperatures during the primary drying stage 